\title{
Os limites da participação: as gestões municipais do PSB em Natal e Maceió
}

\author{
Lindijane de Souza Bento Almeida*
}

\section{Resumo}

A ampliação das experiências de participação da sociedade civil na gestão pública tem ocasionado uma grande diversidade de resultados, mesmo quando levadas a cabo por grupos pertencentes a um mesmo partido ou a uma mesma tendência ideológica. Assim, a questão que nos impulsionou à investigação direcionava-se a analisar por que o projeto de gestão participativa se realiza em formatos diferentes, mesmo quando os gestores pertencem a um mesmo partido e seguem o mesmo discurso. A análise comparativa das duas experiências (Natal e Maceió) demonstrou que há semelhanças, mas, apesar de ambas estarem atreladas ao mesmo projeto político-partidário, há também diferenças, em termos: do avanço do projeto, principalmente em decorrência da peculiaridade do trabalho de base realizado pelos partidos de esquerda junto ao movimento popular; do tipo de coalizão governista que se formou no município e do legado institucional deixado pela gestão anterior.

Palavras-chave: gestão pública, participação social, democracia, clientelismo.

\section{Introdução}

$\mathrm{N}$

o Brasil, a ampliação das experiências de participação da sociedade civil na gestão pública (pelo menos como proposta) tem motivado uma grande diversidade de resultados, mesmo quando levadas a cabo por grupos pertencentes a um mesmo partido político ou a uma mesma tendência ideológica.

* Professora do Departamento de Políticas Públicas (DPP) da Universidade Federal do Rio Grande do Norte (UFRN), Natal. Endereço eletrônico: lindijane@cchla.ufrn.br. 
A análise de experiências de governo pautadas no discurso da gestão participativa nos mostra que há diferentes formas de se viabilizar esse discurso. Pouco a pouco, esse modelo de gestão vem sendo incorporado pelos partidos políticos presentes na arena política nacional, mas cada um criando algum tipo de especificidade em relação a esse modelo. O PT, por exemplo, definiu um "modo petista de governar", que tem o orçamento participativo como carro-chefe. O PSB, por sua vez, também defende um novo modelo de gestão democrática, governando com um discurso voltado à participação social.

Esse partido, após retomar suas atividades legais em 1985, vinte anos após sua extinção durante o período do regime militar, tem passado por grandes mudanças, mas ainda apresenta grande preocupação com a inserção popular, resultado da ação dos seus "intelectuais orgânicos", o que se pode verificar a partir de vários documentos partidários. Nestes últimos 23 anos, o PSB apresentou um significativo crescimento, o maior da sua história, tanto em relação ao número de filiados e militantes, como em relação ao número de governadores, prefeitos, senadores, deputados e vereadores eleitos, ainda que esse crescimento tenha sido acompanhado pela perda de sua identidade socialista.

Para as eleições municipais de 2000, o partido apresentou candidatos à prefeitura em onze capitais, e candidatos a prefeito em 446 outros municípios e 11396 candidatos a vereador. Em 2001, o PSB contava com os governadores de Alagoas, do Rio de Janeiro e do Amapá, e vários prefeitos de capitais - como Natal, Maceió e Belo Horizonte. O governo desses estados e capitais foi conquistado com um discurso voltado para a realização de um novo modelo de gestão, comprometida com a participação popular e a consolidação da democracia.

A análise de experiências de governo do PSB pautada no discurso da gestão participativa mostra-nos que há diferentes formas de se viabilizar esse discurso. Essas experiências se realizam em intensidades as mais diversas, o que tem a ver com as dinâmicas políticas que as respaldam, produzindo resultados diferentes. Al- 
guns municípios governados pelo PSB avançam mais do que outros também governados por esse partido. Isso significa dizer que, mesmo o partido tendo uma só proposta de gestão democrática, na prática essa proposta se realiza de forma diferente. Há governos do PSB que são extremamente progressistas, enquanto outros mantêm traços nitidamente conservadores.

Como o Partido Socialista Brasileiro tem tentado inserir nas administrações municipais o ideal da participação, no Nordeste duas experiências chamaram a nossa atenção - Maceió e Natal. Esse partido esteve governando por três gestões consecutivas em Maceió (1993 a 2004) e quatro em Natal (1993 a 2008), desenvolvendo nelas projetos diferenciados de gestão.

Assim, a questão que nos impulsionou à investigação situa-se na direção de analisar quais as causas da diferença de desempenho de gestões participativas num contexto de projeto político partidário único. Em outras palavras, por que o projeto de gestão participativa se realiza em formatos diferentes, mesmo quando os gestores pertencem a um mesmo partido e seguem o mesmo discurso?

Defendemos a tese de que as especificidades das gestões em estudo vão ser explicadas a partir de uma análise interativa entre a capacidade de organização existente na sociedade, o tipo de coalizão governista e o legado institucional presente nos dois municípios.

Partimos do princípio de que a capacidade de organização da sociedade é uma variável importante para a qualidade da gestão, uma vez que os projetos participativos têm possibilidade de vingar quando a sociedade está organizada. Em nossa opinião, quanto maior a capacidade de organização da sociedade e o capital social nela existente, maior a possibilidade de realização de experiências participativas.

Por outro lado, a intensidade da experiência vai depender também do tipo de coalizão governista - se predominantemente conservadora ou predominantemente progressista. Analisar o papel dos partidos na formação das coalizões e, por conseguinte, 
no desenvolvimento das gestões é de fundamental importância para se avaliar o compromisso com uma gestão participativa. As alianças interpartidárias são mecanismos importantes tanto para o sucesso eleitoral nas disputas para o governo quanto para as ações políticas realizadas. Elas são também imprescindíveis para assegurar as condições de governabilidade.

O legado institucional, a força das instituições criadas pelas gestões anteriores, também pode explicar a diferença entre experiências participativas, uma vez que a existência de arranjos institucionais que tenham como base a idéia da importância da incorporação da sociedade no processo de tomada de decisão, pode dar sustentação às inovações.

O estudo comparativo foi realizado em duas capitais do Nordeste governadas pelo PSB (Partido Socialista Brasileiro), Natal e Maceió — no período que vai de 1997 a 2000 — , com a finalidade de analisar as causas da diferença de desempenho governamental dessas duas experiências. A escolha dessas cidades justifica-se pelo fato de serem duas capitais do Nordeste brasileiro, relativamente semelhantes em relação a quatro características fundamentais: o número de habitantes, a estrutura urbana, o partido que estava no poder, além do fato de estarem sendo, naquele momento, governadas por mulheres.

Nos dois municípios a nossa investigação focalizou: a história da organização popular, os personagens políticos, a coalizão governista que dava sustentação ao governo, a existência ou não de arranjos institucionais que dessem suporte para as inovações municipais (o legado institucional), os traços democratizantes do projeto de governo das duas governantes e os programas prioritários.

Este trabalho está organizado da seguinte maneira. Na primeira parte, apresentamos os casos analisados, através de uma caracterização das capitais analisadas e da trajetória política das governantes. Na segunda parte, trabalhamos de forma comparativa as experiências desenvolvidas a partir de um balanço destas experiências, no sentido de demonstrar os seus resultados em ter- 
mos das inovações realizadas na gestão pública, com vistas à inclusão da sociedade na administração dessas cidades.

\section{O desenho do cenário: Maceió e Natal}

Maceió está localizada no litoral nordestino, possui uma área total de $512,8 \mathrm{~km}^{2}$ e uma área urbanizada de aproximadamente $200 \mathrm{~km}^{2}$. A capital do estado de Alagoas concentra hoje mais de 896.000 habitantes. A quase totalidade da população está na área urbana (mais de 90\%), devido ao alto fluxo migratório da zona rural e do sertão, principalmente nos períodos de entressafra da cana-de-açúcar e de estiagem.

Os grandes problemas nessa capital nordestina são a falta de emprego e a fome, agravados pelo fluxo migratório, que contribui para o fortalecimento do subemprego, da mendicância, e para o aumento do número de favelas. Uma grande parcela da população de Maceió tem baixo poder aquisitivo, o que a caracteriza como uma cidade de alto índice de pobreza. O índice de exclusão social é de $52,64 \%$, e $47,36 \%$ da população está fora do mercado de trabalho. Mais da metade da população $(59,70 \%)$ não tem qualificação profissional. Mais de $50 \%$ da população total desse município não tem nenhum rendimento e, da população economicamente produtiva, apenas $33 \%$ tem rendimento, resultando num coeficiente de desempregados e dependentes de programas sociais da ordem expressiva de mais ou menos $67 \%$.

Além do problema do desemprego, Maceió sofre com a questão da habitação. A estrutura urbana apresenta vários problemas. Com o êxodo rural, uma quantidade significativa de problemas passou a fazer parte da agenda pública do município, principalmente no que se refere à infra-estrutura, a qual é prejudicada pelo próprio traçado topográfico da cidade. Em Maceió apenas $28 \%$ da população é beneficiada com saneamento básico. A pobreza cresce assustadoramente. Em 2000, o Índice de Desenvol-

1 Fonte: Secretaria Municipal de Saúde. 
vimento Humano (IDH-M) de Maceió, de acordo com o Atlas do Desenvolvimento Humano no Brasil, foi de 0.739, o que, segundo a classificação do PNUD posiciona essa cidade entre as regiões consideradas de médio desenvolvimento humano (IDH entre 0,5 e 0,8). De acordo com o Atlas (2000), em relação aos outros municípios do Brasil, Maceió apresenta uma situação intermediária, uma vez que ocupa a 2164ª posição; ou seja, 2163 cidades $(39,3 \%)$ estão em situação melhor e 3343 municípios brasileiros (60,7\%) estão em situação pior ou igual.

No que diz respeito à desigualdade social, podemos dizer que o Índice de Gini passou de 0,62 em 1991 para 0,68 em 2000. A taxa de analfabetismo chama a atenção das autoridades e está ligada ao índice de pobreza e desigualdade do município. Na faixa etária de maiores de 15 anos, ela chega a $8,1 \%$ e, entre os maiores de 25 anos, chega a $18,8 \%$, tornando a educação um grande desafio para os governantes.

Somando-se a essa realidade, Maceió conta com uma história e uma tradição política extremamente conservadora, como todo o estado de Alagoas. Ela é a capital de um estado que tem na cana-de-açúcar o mais importante setor da economia, e a sociedade reproduz fortemente os traços da cultura autoritária e desigual da tradição açucareira.

Essa atividade econômica determinou o aparecimento de duas camadas historicamente definidas, representadas por uma minoria mais favorecida, que, em Maceió, ocupa espaços urbanos organizados e dotados de relativa infra-estrutura, e uma maioria em situação de extrema pobreza, com uma ocupação precária e desordenada. Como há uma alta concentração de renda, gerada pela economia da monocultura da cana-de-açúcar, uma minoria da população detém a maior parte da renda produzida, contrapondo-se a uma realidade de marginalização do processo produtivo da grande maioria da população. A própria estrutura urbana da cidade constitui um exemplo dessa realidade.

A história das relações sociais em Alagoas está diretamente relacionada com a indústria da cana-de-açúcar. Nesse estado nor- 
destino a monocultura da cana-de-açúcar foi mais intensa do que nos outros estados, e ainda é dominante. O quadro político-administrativo que caracteriza a cidade de Maceió traz no seu bojo o peso de uma herança de velhas estruturas conservadoras aliado a fatores estruturais relevantes, como a extrema desigualdade social oriunda da atividade econômica predominante.

De 1993 a 1996 a prefeitura municipal foi ocupada por Ronaldo Lessa, do PSB e, de 1997 a 2004, a cidade teve a Sra. Kátia Born Ribeiro, do mesmo partido, à frente do Executivo municipal. A sua reeleição em 2000, contou com o apoio do então governador Ronaldo Lessa. Uma das estratégias de campanha que ajudou a eleger a prefeita foi a promessa de continuar as inovações do governo Ronaldo e consolidar os projetos que não tinham sido realizados por falta de tempo.

A conquista dos dois mandatos da ex-prefeita Kátia Born chama a atenção para a liderança política que essa personagem tem em Maceió e para o fato de que ela entrou para a história política daquela capital como a primeira (e única) mulher a exercer o cargo de prefeita.

A trajetória política de Kátia Born começou na década de 1980, como militante da área de saúde, quando ela teve uma importante atuação no Sindicato dos Odontólogos e no movimento de mulheres. A sua participação nesse movimento, que foi sendo organizado por ela em vários bairros da cidade, foi intensa e significativa, e teve como um dos resultados a criação do Movimento Feminino do PMDB.

Na campanha de 1996, a prefeita explorou como estratégia de campanha o "sucesso" alcançado na administração do prefeito Ronaldo, que, no final da gestão, obteve mais de $90 \%$ de aceitação popular, chamando a atenção para a avaliação positiva da população em relação à capacidade administrativa do PSB.

Em todos os seus discursos, Kátia destacava a importância da descentralização das ações governamentais e a necessidade de se realizar uma administração democrática, em parceria com a sociedade. Dentro da estratégia de realizar uma administração 
com altos índices de aprovação popular, como tinha sido a gestão Ronaldo, ela prometeu, ao longo da campanha, continuar com os mesmos princípios democráticos e de participação popular defendidos pelo prefeito. Os resultados eleitorais de 2000 em Maceió reafirmaram a liderança política de Kátia, que, pela segunda vez (consecutiva), chega à prefeitura, com uma vitória definida no segundo turno das eleições, demonstrando a preferência da população pela continuidade do seu trabalho.

Natal, assim como Maceió, também está localizada no litoral nordestino, e possui uma área total de $169.9 \mathrm{~km}^{2}$. Segundo informações do IBGE, o município possuía, em 2007, uma população total de 774.230 habitantes, $100 \%$ localizada em área urbana. Segundo o Atlas do Desenvolvimento Humano no Brasil (Perfil Municipal) (2000), o índice de pobreza de Natal naquele ano era de $28,7 \%^{2}$, diferente de Maceió, que apresentava um índice de $38,8 \%$.

No que se refere à desigualdade social, podemos dizer que o Índice de Gini passou de 0,60 em 1991 para 0,64 em 2000. Nos últimos anos, o Índice de Desenvolvimento Humano Municipal de Natal cresceu 7,50\%, passando de 0,733 em 1991 para 0,788 em 2000 (Atlas, 2000). Em relação aos outros municípios do Brasil, Natal ocupa a $838^{\text {a }}$ posição, considerada uma situação boa, frente aos demais municípios brasileiros.

A capital do Rio Grande do Norte apresenta uma configuração socioeconômica diferente da de Alagoas. É uma cidade que se caracteriza, do ponto de vista econômico, pela predominância do setor terciário. O serviço público aparece como o grande empregador, pela alta concentração de unidades militares, repartições federais, estaduais e pela importância da Universidade Federal do Rio Grande do Norte como absorvedora de mão-de-obra qualificada, levando Natal a ser uma cidade onde o setor médio é preponderante.

Diferentemente de Alagoas, o Rio Grande do Norte nunca foi um estado açucareiro. A economia do Rio Grande do Norte não

2 A pobreza foi medida pela proporção de pessoas com renda domiciliar per capita inferior a $\mathrm{R} \$ 75,50$, equivalente à metade do salário mínimo vigente em agosto de 2000 . 
é uma economia centrada na produção da cana-de-açúcar, com a existência de um complexo canavieiro, como em alguns estados nordestinos. Outras importantes atividades econômicas passaram, paulatinamente, a exercer um papel relevante na formação do produto e da renda estadual. Dentre elas, deve-se destacar a exploração e produção do petróleo, através da Petrobras ${ }^{3}$, empresa em expansão no estado desde os anos 70 e que, nas duas últimas décadas, transformou o estado do Rio Grande do Norte no segundo maior produtor de petróleo do país e o primeiro produtor em terra. Daí por que o petróleo constitui uma das principais atividades econômicas desse estado.

Uma das atividades que mais cresceu no estado, dos anos 80 para cá, foi o turismo. Essa atividade tem se destacado na economia potiguar desde a implantação da Via Costeira (estrada que faz a ligação das praias do perímetro urbano de Natal a Ponta Negra e que concentra uma grande rede hoteleira). A partir de 1985, ocorre na capital do Rio Grande do Norte um verdadeiro boom turístico. Segundo as estatísticas locais, o turismo tornou-se o responsável por um terço das rendas estaduais e o principal responsável pela sustentação do emprego e da ocupação. Nas duas últimas décadas, a cidade do Natal registrou um avanço considerável em termos de modernização nessa área, avanço que está diretamente relacionado às iniciativas governamentais para explorar esse potencial da capital.

De 1989 a 1992 a cidade teve a Sra. Vilma Maia (PDT) à frente do Executivo municipal. Em 1992, ela deixa o PDT e entra no PSB, seu partido atual. Em 1996, Vilma candidata-se novamente a prefeita de Natal, derrotando a deputada estadual Fátima Bezerra, candidata do PT, no segundo turno das eleições. As duas representavam partidos políticos identificados com possibilidades de renovação do poder, ainda que a candidatura de Vilma tivesse o apoio de forças tradicionais. Naquele pleito, a candidata Vilma de Faria recebeu apoio de diferentes forças partidárias, dentre elas o PFL,

3 É importante salientar que, além da Petrobras, outras empresas nacionais e transnacionais já estão no Rio Grande do Norte para trabalhar na exploração de petróleo e na produção de energia. 
liderado por José Agripino Maia, fato que constituiu um dos alvos de crítica durante a campanha. Opositores argumentavam que sua candidatura era um reforço ao passado oligárquico. No entanto a candidata do PSB procurava mostrar-se como uma força política alternativa. Ela era portadora de um discurso de independência, que se fundamentava nas rupturas realizadas, nas mudanças partidárias e na esfera da vida privada.

O elemento mais forte usado durante a campanha foi o "sucesso" alcançado na sua primeira administração (1989-1992). É interessante ressaltar que Vilma, no final daquele mandato, obteve 92\% de aceitação popular ${ }^{4}$, o que demonstra uma avaliação positiva da população em relação à sua capacidade de administrar a coisa pública. Assim, o elemento mais explorado politicamente durante a campanha, para diferenciar as candidatas, foi a performance de Vilma como prefeita de Natal. O seu discurso estava voltado para sua experiência e competência. Como ela havia sido avaliada positivamente pela população, a referência a obras realizadas na cidade durante a sua administração constituiu o argumento central que utilizou para promover sua campanha.

Em todos os seus discursos, Vilma fazia referência à importância da descentralização das ações governamentais, à necessidade de se fazer uma administração compartilhada com a sociedade, dentro dos princípios estabelecidos na nova Constituição, o que encontrava respaldo no programa de governo apresentado à população ao longo da campanha. $\mathrm{O}$ aumento da participação da sociedade, para ela, criava possibilidades de um desempenho efetivo de qualquer governo, concretizando a democracia em sua forma plena.

Em novembro de 1996, Vilma de Faria elege-se prefeita da cidade do Natal, tornando-se a primeira mulher a assumir o Executivo municipal por duas vezes. A coligação PTB-PCB-PFL-PSB-PV, formada para a eleição da prefeita, contou com a presença de partidos conservadores, que passaram a ocupar cargos durante o

4 Fonte: FRANCISCO, Paulo. Vilma: eu tenho a melhor proposta. O Poti, Natal, 13 de out. 1996, Política, p.03. 
governo. Além desses partidos, os próprios familiares da prefeita ocuparam um número expressivo de cargos.

Os resultados eleitorais de 2000 reafirmaram a liderança política de Vilma de Faria, que, pela terceira vez, chega à prefeitura (a segunda consecutiva), com uma vitória definida no primeiro turno das eleições, confirmando os resultados das pesquisas eleitorais realizadas durante a campanha. Vilma obteve 178.016 mil votos, o equivalente a $57,71 \%$ dos votos válidos. Assim, ela conquista o seu terceiro mandato para a prefeitura de Natal com uma maioria superior a 87 mil votos sobre Fátima Bezerra, que foi novamente sua principal adversária, o que demonstra a preferência da população pela continuidade do seu trabalho. Esse resultado permitiu à prefeita Vilma continuar à frente do Executivo municipal, entrando para a história do Rio Grande do Norte como a primeira e única mulher que por três vezes exerceu esse cargo.

\section{Um balanço comparativo das duas gestōes}

A análise comparativa das duas experiências por nós investigadas demonstra diferenças marcantes, principalmente em relação à história política dos municípios e à trajetória das governantes. Apesar disso, também há semelhanças, que estão, sobretudo, na forma de governar das prefeitas e na ênfase que elas dão ao discurso da participação da sociedade como elemento sustentador da gestão, o que se pode explicar pelo fato de ambas pertencerem ao mesmo partido político.

O projeto político do PSB tem como premissa "quebrar com o sistema de dominação, recuperando a Federação e promovendo a distribuição do poder e a participação popular". Entre seus objetivos programáticos, o partido aponta para a necessidade de "democratizar o Estado através de mecanismos que garantam a participação da sociedade civil organizada na formulação, execução e fiscalização das políticas públicas".

As experiências de gestão municipal por nós analisadas aponta para direções diferentes na realização dessas propostas. 


\subsection{Organização da sociedade}

Quando olhamos comparativamente para as gestões municipais de Natal e Maceió, chama-nos a atenção as diferenças em relação ao cumprimento do que rezam as premissas do partido em termos da necessidade de se introduzir a participação social em suas administrações.

Qualquer projeto participativo será mais ou menos exitoso se existir uma sociedade organizada, e esta for incorporada nesse projeto. A história de organização social é mais ou menos a mesma nas duas cidades. Em nenhuma delas existe uma tradição de associativismo mas, em Maceió, a presença dos partidos de esquerda nos movimentos de bairro faz alguma diferença. Esses partidos, ao realizarem um trabalho de base, principalmente na periferia da cidade, de alguma maneira ajudam a qualquer projeto de participação. Em Natal, isso não existia: os partidos de esquerda estiveram colados a movimentos associativos de classe média, não tendo referência nos movimentos populares. Aqui, as próprias federações, que aglutinavam o movimento associativo, foram criadas pelos partidos que ocuparam o poder nos períodos anteriores, uma pelo grupo do ex-governador José Agripino Maia (PFL) e outra pelo grupo do ex-governador Garibaldi Alves (PMDB); ao contrário de Maceió, onde, das três federações criadas, uma foi iniciativa de grupos políticos ligados ao PT e outra de grupos políticos do PC do B.

Uma outra diferença em relação aos movimentos sociais é o fato de que a própria governante de Maceió tinha uma trajetória política no movimento de mulheres e no movimento sanitarista, o que constituía um diferencial em relação a prefeita de Natal. Esta, iniciou a sua trajetória política como primeira dama do estado e a partir de então começou a desenvolver um trabalho de criação das associações de cima para baixo, o que lhe deu um respaldo político no chamado "movimento comunitário".

Apesar dessas diferenças, uma característica comum às duas prefeitas é o contato direto que elas fazem questão de manter com a comunidade. Isso lhes assegura uma imagem do governante que trabalha em parceria com a sociedade e que está aberto à partici- 
pação popular. Essa característica das prefeitas se constitui numa estratégia para a manutenção da governabilidade, uma vez que esta, em última instância, refere-se à capacidade de obter apoios, de conseguir a confiança da sociedade organizada e dos partidos políticos. Esse contato que tanto Kátia como Vilma mantêm desde o início das suas trajetórias revelou-se uma estratégia que muito tem ajudado na manutenção de um certo nível de governabilidade das respectivas gestões. Isso porque, a partir do momento em que a prefeita tem a capacidade de estabelecer uma certa relação de proximidade e confiança com a comunidade, as perspectivas de apoio, às vezes até incondicional, da população aumentam consideravelmente.

Em Natal, a base de apoio popular que a prefeita tem, principalmente com as lideranças comunitárias, é um fator importante para o controle da situação de governo. O vereador Emílson Medeiros chama a atenção para essa característica da prefeita de Natal:

uma coisa que caracteriza muito a administração dela é essa interação com a comunidade [...], em que é feito o levantamento necessário com a população [...]. Existe uma afinidade muito grande da administração de Vilma com as lideranças comunitárias. Em cada bairro eles são efetivamente ouvidos no levantamento das questões. Obviamente que, após esse levantamento, há um nível de prioridade, de decisão política, que é tomada por ela e pelo seu secretariado (MEDEIROS, 2000).

As lideranças comunitárias exercem um papel importante ao longo das gestões analisadas. Os líderes comunitários hoje são "agentes" tanto de Vilma como de Kátia, na medida em que são eles que organizam a comunidade de forma a atender os objetivos das prefeitas. Eles confiam na capacidade de governar delas e, de alguma forma, estão cooperando e compartilhando para que haja uma boa administração. Eles se apresentam como os principais atores incorporados ao contexto da governança.

No entanto, de acordo com a prefeita de Natal, as lideranças comunitárias têm uma ação limitada, pois não participam do processo de formulação dos projetos, nem mesmo dos programas 
da área social. Segundo ela, "na elaboração dos projetos propriamente ditos não ocorre a participação das lideranças comunitárias, mas ocorre na definição das idéias, dizendo aquilo que é importante para cada comunidade" (FARIA, 2000).

A forma de governar da prefeita de Maceió é semelhante à da de Natal. Ali, a prefeita também abandona o gabinete e vai visitar obras, e escuta as lideranças comunitárias em audiências. O secretário de Educação ressalta: "a grande marca da gestão da Kátia Born foi justamente ouvir a população, e isso foi mais forte no primeiro mandato, que foi justamente quando ela implementou o orçamento participativo. As regiões administrativas tiveram uma produtividade maior" (QUINTELLA, 2004).

O secretário de Planejamento também destaca essa característica da prefeita, inclusive chamando a atenção para a utilização de tal característica em favor da política Kátia:

\begin{abstract}
Uma marca da prefeita Kátia é o personalismo, em cima do carisma popular, da personalidade. [...] Kátia é uma pessoa que bota a mão na massa, então isso aí dá um contato dela com o povo muito forte, o contato direto. E o povo adora aquele jeitão dela, e ela utiliza muito bem isso, e aí vem ascensão [...] muito mais política que administrativa. Então administrar é consequiência do que o político permite, e não administrar bem para gerar um novo contexto político. E até certo ponto, eu volto a dizer, a nossa política ainda é de mão forte, de pessoas de mãos fortes, são pessoas que não expressam, de cunho pessoal, justamente para se referir a estas políticas pontos de agregação, pontos de catalização dessas energias. Então, existe, em Alagoas ainda existe o personalismo político muito forte (SILVA, 2004).
\end{abstract}

Constatamos, tanto em Natal como em Maceió, que a marca das prefeitas consiste no seu estilo de desenvolver uma administração que prioriza o contato direto com a população como a forma principal de se levantarem as demandas da sociedade, mas nunca de deliberar conjuntamente. Dentro dessa perspectiva, ouvir diretamente a comunidade acerca das suas necessidades se apresenta como uma estratégia de significativa importância para a legitimidade da gestão e para o aumento da liderança política das governantes. 
Nas gestões analisadas, as prefeitas utilizam uma forma bem pontual para conhecer as demandas da sociedade: as audiências públicas. Na verdade, a prefeitura de Natal não tinha como fazer um trabalho mais sério de levantamento de demandas, como na experiência do Orçamento Cidadão de Maceiós. O levantamento das demandas, na administração Vilma, resumia-se apenas ao contato direto da governante com o povo, atendendo de forma imediata aos apelos da comunidade.

Conforme o depoimento de alguns vereadores, esse estilo de governar demonstra que, apesar de a governante apresentar um discurso voltado para a participação e a cidadania, ainda reproduz um tipo de relação que está baseado no favor, na dádiva, no contato pessoal, e não num direito estabelecido pela própria Constituição brasileira. Assim, aquilo que é de direito do cidadão, como, por exemplo, o direito à saúde, transforma-se em favor quando este é atendido pelo Programa Nosso Bairro Cidadão ${ }^{6}$, no

5 A experiência do Orçamento Participativo em Maceió, denominado Orçamento Cidadão, para se diferenciar do OP que se realiza nas gestões do PT, teve início com a vitória do PSB na eleição para prefeito em 1996, sendo implantado na gestão municipal em 1998, um ano depois da posse da prefeita Kátia Born (PSB). O Programa Orçamento Participativo foi instituído através do Decreto ㄲo 5.753, de 10 de março de 1998, denominado Orçamento Cidadão, tinha o objetivo de assegurar a participação popular na elaboração anual da proposta orçamentária. Além do Decreto no 5.753, o Programa Orçamento Cidadão teve respaldo legal na Lei Orgânica do Município de 03-04-1990 e no plano de governo da prefeita Kátia Born, que apresentava o Orçamento Cidadão como uma prioridade, uma vez que a participação popular era uma das estratégias para consolidar o caráter socialista e ético da gestão

6 O referido programa consistia na realização de reuniões da prefeita e seus secretários nos bairros da cidade. A estratégia consistia em aproximar o governo do cidadão, na medida em que possibilitava criar, entre as partes, um diálogo mais próximo, capaz de gerar a confiança da sociedade nos seus governantes. Nessa perspectiva, o programa apresentava como missão levar o governo municipal às comunidades, de forma integrada e sistemática, tendo como proposta o resgate da cidadania. Podemos observar que a prefeita Vilma implantou esse programa com um discurso voltado para a construção da cidadania. No entanto partimos do princípio de que a cidadania se realiza no cotidiano, e não em situações especiais. Para nós, o bairro é cidadão se ele conta, o tempo todo, com assistência médica, atendimento odontológico, etc., e não de forma esporádica, quando é escolhido pelos coordenadores do evento para receber esses atendimentos. Olhando para a realização do Nosso Bairro Cidadão, podemos caracterizá-lo como um programa que acabava tendo um caráter muito assistencialista, um tipo de assistencialismo travestido de participação cidadã. 
qual a equipe médica, que deveria estar no posto de saúde do município, vai para um estande num determinado bairro, durante três dias, para prestar o serviço.

Segundo o vereador de Natal Fernando Mineiro, Vilma "é uma política muito competente na arte da política tradicional. Ela tem capacidade, por exemplo, pra fazer o contato direto com a liderança, alimentar o populismo, o clientelismo. Isso vai consolidando a sua estrutura e a sua referência na cidade". Para ele, a prefeita conseguiu consolidar a sua popularidade respondendo ao imediatismo da população em várias questões: "quer seja no calçamento, quer seja tapando buraco, quer seja dando uma cesta básica, quer seja, por exemplo, dando $\mathrm{R} \$ 25,00$ (vinte e cinco reais) à criança que está na escola, ou combinando com uma política ofensiva, competente de marketing, televisivo particularmente" (MINEIRO, 2000).

Na verdade, a existência de programas do tipo Nosso Bairro Cidadão demonstra a prioridade que a prefeita dá ao imediatismo das ações. Se ela precisa ir com o médico, o dentista, o assistente social para um bairro, isso, de alguma forma, é um sinal de que a unidade de saúde municipal está deixando muito a desejar em termos de funcionamento permanente.

Em se tratando de Maceió, podemos chamar a atenção para o fato de que a não-continuidade do Programa Orçamento Cidadão na administração Kátia tem a ver com a preocupação com o imediatismo das ações. Como afirma Judson Cabral (2004),

ela [...] faz uma política muito voltada pra resultado, relações imediatas, muito numa visão populista, e nunca de projetos. Não demonstrou ser uma política com propostas e um projeto claro voltado para objetivos da área que ela se propôs, num mandato que ela se propôs. Apesar da experiência anterior dela como vereadora, $[\ldots]$ de uma grande habilidade na relação pessoal, $[\ldots]$ do ponto de vista da política voltada pra execução dos interesses mesmo da cidade, como prefeita, ao nosso ver, ela foi um tanto desastrosa. [...] A prefeita Kátia Born trabalha muito em cima de resultados aparentes e resultados imediatistas, e nunca num projeto de alcance maior, [...] mais arrojado, um projeto que tivesse 
começo, meio e fim, dentro de uma visão de médio e longo prazo. [...] A prefeitura de Maceió, no período da Kátia Born, não conseguiu dar continuidade ao que se esperava; foi uma grande frustração em relação ao mandato do PSB anterior, que foi do prefeito Ronaldo Lessa.

O vereador Régis Cavalcante, que fez parte da bancada de Kátia Born na Câmara, também chama a atenção para a forma tradicional de fazer política da prefeita. Em sua opinião, a gestão dela pode ser considerada como:

uma administração arcaica, atrasada, que não rompeu [...] essa coisa verticalizada de estabelecer relações com o Poder Legislativo como uma extensão do Executivo, que é uma marca dos anos 50, do século passado, uma forma atrasada de fazer política: impulsiva, corporativa, verticalizada. [...] Nas relações políticas com as lideranças, com os vereadores, ela não cria um processo educativo de apoio às discussões, e com isso termina contaminando a própria sociedade: as lideranças de bairros são verdadeiros cabos eleitorais [...] Em todo momento ela teve essa forma clientelista, de cooptação; ela nunca teve problemas de governabilidade, nenhuma dificuldade nisso. (CAVALCANTE, 2004).

No que diz respeito ao papel das lideranças comunitárias, em Maceió o representante da Federação das Associações de Alagoas (FAMAL) também ressaltou a posição da prefeita como sendo diferente da de Ronaldo Lessa, uma vez que ela não deu continuidade ao trabalho que vinha sendo feito no governo anterior e cooptou lideranças comunitárias através de cargos na prefeitura.

Essa é também a opinião do vereador Judson Cabral (PT), levantando as dificuldades para a implementação do Programa Orçamento Cidadão, que, como ele diz, "não logrou êxito, porque não houve responsabilidade na conduta desse projeto...”. A prefeita Kátia teve uma habilidade muito grande em cooptar as lideranças comunitárias. Diz Cabral (2004):

Foi uma grande marca do governo dela e do partido dela. Na minha avaliação ela... assim... desvirtuou a participação das associações comunitárias, associações de bairro, cooptando as lideranças 
através de cargos comissionados, de convênios e de pequenas obras onde eles eram quem manipulava a parte financeira, e isso gerou uma cultura, um vício muito grande dessas lideranças em não mais representar a comunidade, e sim defender interesses que os favoreciam.

A inexistência de uma comunidade cívica em Natal e em Maceió levou as governantes a criarem artifícios políticos para forjar um envolvimento da população. A valorização da sociedade é produzida artificialmente pelo governo, que utiliza o poder para criar mecanismos que garantam uma relação de proximidade com a população, principalmente com a mais carente. Divulga-se uma noção de proximidade do governante com a comunidade no sentido de forjar uma participação social que possa sedimentar uma relação de confiança entre o governante e a população de um modo geral. Isso porque a eficácia do governo, como lembra Putnam (1996), depende muito do nível de intercâmbio entre ele e a sociedade.

As administrações de Natal e Maceió, durante o período analisado, são experiências de gestão municipal que se intitulam democráticas, mas que apresentam especificidades na implementação da gestão participativa. As ex-prefeitas das capitais estudadas tiveram a iniciativa de implantar um programa com o discurso de trazer o cidadão para dentro do governo, tentando demonstrar que há no governo um espaço aberto à participação da sociedade não só na tomada das decisões de interesse coletivo mas também no planejamento e na execução das ações, o que se mostrou um caminho eficiente para manter a governabilidade da gestão, assim como aumentar o capital político das governantes. No entanto a participação popular era entendida pelas duas prefeitas como uma participação meramente consultiva.

As ações do governo Kátia em torno da continuidade do Orçamento Cidadão, em Maceió, e a sistemática do Nosso Bairro Cidadão, em Natal, nos levam a esse entendimento. Tanto em Natal como em Maceió os programas oriundos da administração municipal com o objetivo de desenvolver uma gestão mais democrática não obtiveram êxito nesse sentido, mas, no que diz respeito ao 
seu uso para aumentar o capital político da governante, principalmente através do marketing político, foram importantíssimos para passar uma imagem de abertura do espaço público à participação social, que, na prática, aconteceu muito pouco.

Analisando as gestões, pudemos ver que, a começar pela variável capacidade de organização social existente em Natal e em Maceió, há uma diferença, que está diretamente relacionada ao trabalho de base organizado pelos partidos de esquerda nas duas capitais.

Como ressaltou a prefeita Kátia Born (2004), em relação a Maceió, “o PSB sempre teve um vício, um bom vício de discutir com a sociedade civil organizada, o PSB é um partido que tem o maior número de militantes de associações de moradores e de delegados de bairros". Esse "vício" do PSB, esse trabalho de manter um contato direto com as lideranças de bairro é uma realidade de que a grande maioria da população tem conhecimento, ou seja, na cidade há uma imagem do PSB como o partido que consegue exercer uma forte influência sobre as lideranças comunitárias. Mas, claro, encontramos várias explicações para essa influência acontecer.

Num país como o Brasil, onde só há muito pouco tempo foram ampliados os espaços de participação, os mecanismos coercitivos e de controle do aparelho estatal sempre funcionaram como entraves à organização social. A forte ação do governo (estado e município), que intensifica a sua política assistencialista usando as organizações populares, criando conselhos comunitários, federações, etc., apresenta-se como uma das explicações para o baixo nível de organização popular nas duas experiências por nós analisadas.

Como em Natal e Maceió inexiste uma tradição de luta urbana, a população desorganizada dessas cidades pôde, e ainda pode, tornar-se "massa de manobra" dos poderes públicos, ainda que em Maceió tenha havido resistência dos grupos de esquerda. Várias das organizações de moradores foram criadas com forte influência de políticos e do próprio Estado, superpondo entidades, criando associações paralelas, para as quais carreavam benefícios de diver- 
sos tipos.

A partir da análise das informações referentes ao levantamento das federações e associações de moradores tanto em Natal como em Maceió, observamos que a maior parte delas foi criada pelo governo local na década de 80 . Grande parte dessas entidades surgiu de cima para baixo, através de um processo de intervenção do Estado, que utilizava o discurso da participação. A criação das associações teve seu ponto culminante em 1984 e 1985, período que corresponde à preparação das eleições diretas para a prefeitura das capitais.

\subsection{Tipos de coalizões políticas}

Outra variável importante para se entender os avanços ou entraves à implementação de propostas inovadoras é de natureza nitidamente política e se refere ao tipo de coalização construída para viabilizar o governo. A coligação formada para a eleição define também o estilo de governo, uma vez que os cargos mais importantes são distribuídos pelos partidos que compõem a coligação. No caso de Natal, durante a gestão Vilma foi forte a presença de familiares da própria governante na composição do governo, assim como de representantes dos partidos conservadores que compunham a coalizão governista.

Na coligação realizada para a eleição de Kátia Born, foi o partido da prefeita que teve um número significativo de secretarias: mais de $50 \%$ delas foram ocupadas pelo PSB; mas os demais partidos também foram contemplados com cargos, embora em um número menor. O PPS, por exemplo, partido que naquele momento representava uma força de esquerda importante, ocupou a Secretaria de Promoção da Cidadania e Assistência Social.

A coalizão governista de Maceió (PSB, PC do B, PST e PPS) era mais progressista do que a de Natal (PTB, PCB, PFL, PSB e PV), porque Vilma sempre fez coligação com os partidos conservadores, principalmente PFL e PTB, que brecavam avanços democratizantes.

Em Maceió, a participação dos partidos de esquerda foi bem diferente. A atuação do PC do B, por exemplo, definiu a trajetória 
das lutas urbanas e do poder municipal. Mesmo com a inexistência de uma forte estrutura produtiva moderna, de um grande parque industrial que contasse com uma forte presença de um operariado definido, a esquerda conseguiu manifestar-se, chegando inclusive à prefeitura de Maceió. As eleições de 1996 foram disputadas por duas coligações de partidos de esquerda: a coligação PT-PSTU, com a candidata Heloísa Helena, e a coligação PC do B-PST-PPS-PSB, com a candidata Kátia Born.

A capacidade de um governante implementar ações depende do respaldo que ele tem, principalmente, no Legislativo (Congresso, Assembléias Estaduais e Câmara de Vereadores). Assim, o apoio político que o gestor é capaz de sustentar no plano legislativo é fundamental para a concretização de decisões. Uma característica tanto da prefeita de Natal como da de Maceió em todos os mandatos de ambas foi a de terem sempre uma forte base de apoio político nas instâncias decisórias, principalmente na Câmara de Vereadores.

Em Natal, durante a gestão analisada, a prefeita contava com uma base de sustentação formada pelos partidos: PSB, PMN, PFL e PSDB, que se coligaram para a sua eleição ${ }^{7}$. No movimento organizado pela prefeita com vistas à sua reeleição, a partir de meados de 1999, firma-se um acordo da prefeitura com o governador do estado, passando a base de apoio da prefeita a ser formada também pelo PMDB e pelo PPB. Isso afasta os seus antigos aliados, José Agripino, do PFL, e Geraldo Melo, do PSDB, demonstrando o movimento pendular da prefeita entre os dois grupos políticos dominantes no estado.

Nessa ocasião, a histórica ligação de Vilma com o PFL, partido que garantiu o seu apoio tanto para a conquista do primeiro mandato quanto para a do segundo, retira-se da base de apoio quando a prefeita, para viabilizar a terceira gestão, vai buscar o apoio do PMDB e do PPB, a coligação vitoriosa em nível de governo do estado.

7 No fim da gestão, o PFL e o PSDB passaram a fazer oposição à prefeita, em virtude de esses partidos terem lançado a candidatura da vereadora Sonali Rosado nas eleições municipais de 2000. 
Em virtude dessa aliança firmada entre a prefeita e o governador, ocorre a adesão de mais quatro vereadores, que antes faziam oposição a ela, passando a fazer parte da bancada governista na Câmara e garantindo uma base de sustentação política constituída por mais da metade dos partidos políticos representados na Casa. Durante quase toda a gestão de Vilma, dos 21 vereadores que compõem a Câmara, 18 sempre estiveram dando apoio à prefeita, ficando de fora apenas o Partido dos Trabalhadores (PT) e o Partido Comunista do Brasil (PC do B).

Quanto à prefeita de Maceió, durante a sua primeira gestão, ela contava com uma bancada de sustentação formada pelos partidos PSB, PC do B, PPS e PST, que se coligaram para a sua eleição. Da mesma forma que em Natal, durante toda a sua administração, dos 21 vereadores que compõem a Câmara, 18 estiveram dando apoio à prefeita, ficando de fora apenas o Partido dos Trabalhadores (PT).

Na verdade, a grande questão que nos chamou a atenção, tanto em Natal como em Maceió, foi como as prefeitas conseguiram ter uma maioria tranquiila na Câmara, formalizando sempre um acordo que viabilizasse todos os seus projetos, o que, de alguma forma, demonstrava a aceitação de suas ações à frente da administração municipal. Esse acatamento de propostas e projetos por parte da maioria dos vereadores pode ser explicado de diferentes pontos de vista, que oscilam da relevância dos projetos para a melhoria da qualidade de vida da população até a manutenção de relações clientelistas por trás do apoio que as prefeitas vêm tendo no Legislativo.

Para esses vereadores, o apoio político que Vilma tem sempre conquistado da Casa Legislativa se explica por outras negociações políticas, que, na maioria das vezes, incluem o apoio do Executivo municipal a fundações criadas por vereadores com a finalidade de atender à população, principalmente àquela mais carente. Na concepção deles, a prefeita lança mão de recursos públicos para a realização de seus objetivos, na medida em que favores de vários tipos são trocados por apoio e por votos. Isso tudo pode ser exemplificado com os seguintes depoimentos: 
A prefeita negocia com o toma-lá-dá-cá com os vereadores. Ela sempre teve maioria, tanto no primeiro governo como agora, e tem uma bancada fiel a ela no sentido de garantir cargos, de trocar cargos com os vereadores, de trocar subsídios pras entidades dos vereadores, isso que é uma questão pública e notória inclusive na cidade. [...] Ela consegue aglutinar a adesão pelo conjunto do uso que ela faz da máquina, da rede que ela cria. Então, na Câmara, ela tem essa relação, ela negocia os seus projetos com a sua bancada, que é fiel ao toma-lá-dá-cá (MINEIRO, 2000).

\section{E outro vereador:}

É porque ... primeiro, nós temos o grande câncer na política local, que são as fundações, a grande maioria delas mantida pelo Poder Executivo, com o dinheiro do povo, para que os vereadores façam assistencialismo eleitoreiro com a miséria da população. Segundo, nós temos os cargos comissionados dentro da prefeitura, na sua grande maioria loteados pelos vereadores. Essas duas coisas eu posso falar sem ser leviano, tendo condições de comprovar, [...] mas infelizmente aqui na Câmara eu posso afirmar que o que estabelece a maioria dela aqui nesta Casa [...] é exatamente a cultura do é-dando-que-se-recebe, e essa cultura se expande até a classe empresarial, estabelecendo uma relação de clientelismo promíscuo do poder público com a iniciativa privada: os favores, as comissões, o assistencialismo [...] (PASSOS, 2000).

Em Maceió, os vereadores da oposição também partem do princípio de que a aprovação dos projetos enviados pela prefeita Kátia está diretamente relacionada à forma de fazer política da prefeita. Assim fala um vereador do PT:

Uma das coisas que ela demonstrou muita habilidade foi na manipulação da Câmara Municipal. [...] e talvez isso tenha sido o grande desastre, porque na medida em que ela cooptou a grande maioria da Câmara, através de, eu diria, do jogo de interesse, onde os vereadores tinham, boa parte, a participação em secretarias e outras vantagens, e com isso ela perdeu, [...] a fiscalização ficou muito resumida a uma oposição mínima. [...] Ela cuidou em cooptar esses vereadores. [...] Tem um monte de vereadores aqui hoje com fundações, escolas [...] e aí quem paga caro é a sociedade, porque eles fazem tudo isso com uma visão meramente eleitoreira e não de desenvolvimento, de erradicação da pobreza ou de pre- 
venção de doenças; é muito voltado pra resultados imediatistas. Isso infelizmente não leva ao desenvolvimento [...]. A liderança política dela se acentua na relação pessoal, por exemplo, com os vereadores, eu diria, clientelista, assistencialista. (CABRAL, 2004).

Para o vereador Paulo Fernando dos Santos (2004), do PT-PSTU, a prefeita Kátia só conseguiu ter maioria na Câmara Municipal porque, como ele afirma, ela

garantiu o aumento do duodécimo na Câmara...Então isso aí fez com que os vereadores mantivessem essa família. Os vereadores também tinham estrutura de poder dentro da Casa, então todo mundo que era bancada do governo tinha cargo comissionado nas secretarias, tinha trânsito livre, tinha abertura. [...] As fundações de vereadores, é uma moda que foi criada aqui em Maceió... tem várias. Você tem vereadores que não eram do PSB e hoje estão no PSB, que criaram fundações, e quem ajudou muito nos subsídios dessas fundações foi a própria prefeitura. Então uma marca da Câmara de Vereadores sempre foi o assistencialismo. Então, a Kátia ela mantinha fundações, muitas vezes colocava médicos, dentistas, profissionais da saúde à disposição, profissionais da educação, colocava medicamentos; inclusive o Cícero Almeida, que hoje é o candidato em 1 lo lugar, ele foi vereador da bancada da Kátia, ele criou um novo tipo de saúde no município e quem bancava o medicamento era a rede municipal.

É importante salientar que, além dos dois vereadores da oposição, um que fez parte da bancada da Kátia, José Régis Cavalcante (PC do B-PST-PPS-PSB), vereador da coligação que elegeu a prefeita, compartilha da mesma opinião dos vereadores do PT. Diz ele:

Lamentavelmente, a administração da Kátia levou a grandes problemas, dificuldades, que terminamos não apoiando mais a sua reeleição. [...] Ela desestruturou completamente toda a administração que vinha sendo montada já pelo então prefeito Ronaldo Lessa, e começou a ter uma relação promíscua com os vereadores, a quem ela chamava de "meus maridos", uma relação muito ruim, porque foi criada paulatinamente uma série de "deuses" políticos na cidade, o que leva hoje à realidade de Maceió. Em Maceió, essas personalidades políticas têm cada um instituto, uma fundação, 
outro um conjunto habitacional, todos eles alimentados por essa ação paternalista, clientelista da prefeita Kátia Born. (CAVALCANTE, 2004).

De acordo com os vereadores da oposição, nas duas cidades, a base de sustentação de Vilma e Kátia na Casa Legislativa está relacionada ao fato de que essas governantes não conseguiram romper com a origem conservadora e, através do clientelismo, da troca de favores, conseguem manter o apoio de uma maioria esmagadora nessa Casa.

\subsection{Legado Institucional}

Outra singularidade pode ser apontada na experiência de Maceió, no que diz respeito ao legado institucional deixado pelo governo anterior, que já tinha um projeto, que já tinha uma estrutura montada e que, de alguma forma, criava as bases da montagem do projeto do Orçamento Cidadão, o qual, inclusive, teve seu processo de elaboração nesse governo anterior. Enquanto isso, em Natal, o governo que antecedeu a gestão de 1997 foi um governo permeado de contradições, na medida em que o prefeito foi incapaz de montar uma estrutura que possibilitasse mudanças

e evitasse o retorno das forças conservadoras à gestão. É preciso lembrar também que a história das gestões passadas não continha elementos que possibilitassem as mudanças propostas pela gestão Aldo, como, por exemplo, o Orçamento Participativo.

Em Maceió, a história deixada pela gestão Ronaldo foi bem diferente. A forma de administrar desse governante dava condições para a prefeita Kátia realizar suas propostas de mudanças, que corporificavam a participação da sociedade no governo. Nessa capital nordestina, houve uma ruptura, caracterizada como um "momento crítico" segundo a teoria da path dependency (dependência de trajetória), que influenciou a gestão por nós analisada. Dessa forma, em Maceió não se pode falar de Kátia Born sem falar de Ronaldo Lessa, na medida em que foi o governo deste que realizou uma ruptura, que realizou a mudança na gestão pública daquele município. 
Em Natal, é necessário se destacar que a primeira gestão de Vilma (1989-1992) não deixou bases que servissem de suporte para a experiência de 1997. Em linhas gerais, quando assumiu a Prefeitura Municipal de Natal pela primeira vez, Vilma não encontrou nenhuma estrutura que desse sustentação a um projeto diferenciado. O prefeito anterior, do PMDB, era parte de um grupo político tradicional do estado, e não realizou inovações importantes no modo de gestão pública. Naquele momento, a despeito do discurso da participação, bastante divulgado ao longo de todo o governo, nenhum projeto foi experimentado com o objetivo de concretizar esse discurso.

\subsection{Participação: o discurso e a prática}

Uma outra forma de avaliar a intensidade das propostas de participação na gestão dos dois municípios é focalizar a atenção para o papel dos principais conselhos de políticas públicas. Como esses conselhos possibilitam o estabelecimento de novas relações entre governo e sociedade, fizemos uma análise superficial de alguns deles, tanto em Natal como em Maceió, com o intuito de comparar o nível de atuação, ou, melhor dizendo, o real papel desses mecanismos de participação nas gestões analisadas.

Tanto em Natal como em Maceió, o discurso da participação social foi incorporado, está presente nos planos de governo, em alguns programas criados para concretizá-los, no entanto, na prática a realidade é outra: a tradição autoritária e centralizadora do exercício do poder permanece dificultando a adoção de medidas mais descentralizadas e democráticas por parte do Executivo municipal.

De acordo com os dados obtidos tanto em Natal como em Maceió, a partilha do poder de decisão ainda não é algo aceito com facilidade pelas prefeitas Vilma e Kátia, o que dificultou o real funcionamento dos conselhos municipais. A falta de vontade política para mudar as regras do processo decisório, por parte das governantes, principalmente por elas entenderem a participação da sociedade como uma participação puramente consultiva, resultou na constituição de conselhos apenas para cumprir a determinação legal. A experiência concreta de alguns conselhos em Natal 
e em Maceió foi extremamente complicada. Nas áreas da saúde, da criança e do adolescente, da assistência, e do planejamento, a experiência tem demonstrado inúmeros problemas, principalmente em termos da relação desses fóruns com a gestão municipal.

A gestão das políticas nessas áreas acontece nos velhos moldes, sem o reconhecimento dos espaços de participação e de controle social que a nossa Constituição determina. A falta de vontade política das prefeitas, de abrir o governo à participação social, fez com que os conselhos, nos dois municípios estudados, não se apresentassem como espaços de tomada de decisões que contassem com a participação efetiva dos diferentes segmentos da sociedade civil organizada. É importante ressaltar também que não havia, no nível local, uma sociedade civil organizada, com capacidade de produzir novas atitudes políticas. Faltava capital social em Maceió e, principalmente, em Natal para dinamizar os conselhos gestores, levando-os a exercerem a contento o seu papel.

A relação que se estabelecia entre a prefeitura e os conselhos tanto em Natal como em Maceió estava pautada apenas na exigência imposta pela Constituição. Já que a transferência de recursos supõe a existência desses instrumentos participativos, as prefeituras de Natal e de Maceió criaram os conselhos municipais ligados às diferentes áreas de políticas sociais, não permitindo, no entanto, que fossem espaços de participação da sociedade civil no processo de formulação, implementação e fiscalização de políticas públicas.

A análise dos conselhos gestores das gestões Vilma e Kátia demonstra que a participação não se apresenta como uma prioridade de governo, como deixa crer o discurso das prefeitas e dos seus auxiliares, e que a raiz autoritária e a centralização ainda estão presentes no modo de governar.

\section{Considerações Finais}

Dadas as especificidades da história política de Maceió e Natal, várias dificuldades foram apresentadas para o exercício efetivo 
da prática participativa nessas cidades. Essas capitais não contam com uma tradição de organização da sociedade, com a presença de capital social suficiente para formar uma comunidade cívica, caracterizada por uma relação de proximidade do governante com a população, com a finalidade de desenvolver uma gestão pública eficiente.

Robert Putnam (1996, p. 30) chama a atenção para a importância do civismo para o bom desempenho de um governo. Nas duas cidades analisadas, o número de membros de associações socioculturais é muito baixo e distante do ideal de estruturas cooperativas mencionado por Putnam. No entanto, nos últimos anos, mudanças começam a acontecer em Maceió, na medida em que aparecem novas iniciativas de organização social. São criados conselhos municipais de duas categorias diferentes: uma que é obrigatória e exógena, devido às legislações das outras instâncias de governo (algumas definidas para a destinação de recursos relacionados a programas sociais); e outra que é resultado de decisões locais, portanto endógena (VIEIRA E LINS, 2003).

A questão não é se o funcionamento se dá a contento ou não, mas só o fato de eles serem fruto de escolhas e decisões locais merece destaque, uma vez que são espaços de decisão para a prática democrática, ou seja, para a participação da sociedade civil na política. Como a participação é um processo de socialização, é um processo educativo (PATEMAN, 1992), a criação desses conselhos é de significativa importância.

Segundo os dados coletados pela pesquisa, no caso das federações e associações de moradores existentes em Natal e Maceió, havia uma estreita relação dessas entidades com os aparelhos de Estado e os partidos políticos a que muitas de suas lideranças estavam atreladas. Essas lideranças participam de um jogo de interesses, no qual há, de fato, uma troca de favores. Porém, a vitória eleitoral do candidato dos partidos chamados progressistas, na década de 90, em Maceió, numa coalizão liderada pelo PSB, apresentou perspectivas de mudanças. A continuidade conservadora, que vinha caracterizando a história política de Alagoas, foi 
rompida com a vitória de candidatos de partidos de esquerda nas eleições majoritárias e proporcionais. Como ressalta Vieira e Lins (2003, p. 176),

apesar de sua história política tradicional e conservadora e das profundas desigualdades sócio-econômicas, Maceió incorporou inovações no seu discurso político e na sua estrutura institucional, legal, política e administrativa que hoje fazem parte de contextos urbanos menos conservadores e desiguais.

Isso certamente é resultado, na história recente, de uma participação significativa dos partidos de esquerda, os quais têm ajudado a definir a trajetória das lutas urbanas. Essa atuação tem sido contínua e forte, o que explica a politização dos movimentos e a vitória eleitoral de candidatos dessas agremiações. A conquista da prefeitura em três eleições seguidas, por candidatos com inserção no movimento popular, é uma prova desse crescimento. Analisando as gestões, pudemos ver que há uma diferença, que está diretamente relacionada ao trabalho de base organizado pelos partidos de esquerda nas duas capitais.

Na realidade de Natal, as federações e associações de moradores são, em sua grande maioria, ligadas a partidos políticos de centro-direita ou ao aparelho de Estado, e não constituem organizações como representações da coletividade. Os partidos de esquerda não funcionaram como elementos de fortalecimento dos movimentos sociais. O que aconteceu, e ainda acontece, na realidade dos movimentos sociais urbanos dessa cidade é a utilização de tais movimentos como elementos de fortalecimento de políticos individuais e de estruturas partidárias conservadoras. Estes interferiram nos rumos dos movimentos a partir do momento em que passaram a manipulá-los.

Outra diferença verificada nas gestões municipais analisadas está diretamente relacionada a vitória de Ronaldo Lessa nas eleições de 1996, que rompe com o conservadorismo político até então existente em Maceió e inova a gestão pública, priorizando a descentralização administrativa e a participação popular. De acordo com os teóricos do conceito de path dependency (dependência 
de trajetória), podemos chamar a atenção para o fato de que a chegada ao poder de um candidato de um partido de esquerda constituiu-se, para a história da cidade, um momento crítico.

A idéia de fazer um orçamento participativo começou a ser pensada e elaborada no governo Ronaldo Lessa; no entanto esse programa não foi implantado durante aquele governo, mas foi utilizado como carro-chefe na campanha eleitoral que elegeu Kátia Born prefeita da cidade. A promessa de realizar a experiência do orçamento participativo em Maceió foi bastante ressaltada no período de campanha, o que se respaldava na estrutura criada para desenvolver a administração Ronaldo e na promessa da candidata de continuar as ações do seu antecessor que, por falta de tempo, não tinham sido implementadas. Na gestão Kátia, realmente, a estrutura administrativa montada no governo anterior serviu de base para a construção da proposta do Orçamento Cidadão de Maceió.

A gestão que antecedeu a administração da prefeita Vilma de Faria foi a gestão que teve os partidos progressistas PC, PC do B, PSB, PDT e PV à frente do Executivo municipal. Esses partidos chegaram à prefeitura de Natal através de uma coalizão intitulada Frente Popular de Natal, que tinha como líder a prefeita Vilma de Faria (PDT).

O governo da Frente Popular, não conseguiu cumprir suas promessas. As propostas de campanha não conseguiram sair do papel devido a uma crise de governabilidade que se instaurou, consequiência da falta de capacidade do governante em ter e manter uma bancada na Câmara Municipal que o apoiasse e desse sustentação a seus projetos.

Um governo tem que ser capaz de construir bases de sustentação política para manter um certo padrão de governabilidade. A gestão de Aldo Tinoco não foi capaz de incorporar novos atores ao contexto do governo, não atuando na dimensão da participação e da partilha do poder decisório com a sociedade. Mesmo tendo iniciado o seu governo respeitando o processo de democratização, descentralizando o poder político e administrativo, inclusive tentando implantar o Programa Orçamento Participativo, esse 
governo não teve capacidade de dar continuidade ao programa e realizar realmente uma gestão participativa que apresentasse um saldo positivo no final do governo.

Um balanço das gestões Vilma e Kátia demonstra que ainda existe uma distância em relação à consolidação de uma administração calcada na ampliação do espaço público à participação da sociedade, como mecanismo de controle social. Apesar de a prefeita Vilma ter criado o Programa Nosso Bairro Cidadão e a prefeita Kátia o Programa Orçamento Cidadão para estabelecer um contato mais direto com a sociedade, o estilo de gestão delas não corresponde ao modelo de gestão participativa na área das políticas públicas que a Constituição propõe.

A avaliação feita por diferentes segmentos da sociedade, em relação ao Orçamento Cidadão, é contraditória. A prefeitura tem uma avaliação positiva do programa OC, enquanto a própria coordenação deste, vereadores da bancada da prefeita e representantes da comunidade (delegados) reclamaram da falta de apoio para a sua plena consolidação. Diante disso, partimos do princípio de que a prefeitura adotou, sim, no seu discurso e no aparato institucional, as inovações que fazem parte de uma gestão democrática e participativa, mas a prática mostra que, na realidade, a participação popular na administração municipal de Maceió foi um processo que, começou a existir, mas não foi sendo reforçado e estimulado pela gestão para ter continuidade.

A gestão Kátia, que incorporou no seu discurso e no seu aparato institucional legal, político e administrativo a democracia participativa, na prática não conseguiu consolidá-la, uma vez que traços da política tradicional continuaram a predominar durante a sua administração. A implantação do OC em Maceió se deu de forma positiva, existindo num primeiro momento uma participação direta da população na definição de parte dos recursos públicos, assim como uma disposição do governo para que esse programa se consolidasse, sendo fundamental para a sua continuidade a credibilidade por parte da população, que seria definida com o cumprimento das obras pela prefeitura ao longo do ano. No entanto, 
como isso não ocorreu, o programa sofreu um grande desgaste, deixando a desejar, em termos de realizações.

É preciso ressaltar que o Programa Orçamento Cidadão não se realizou da forma como foi pensado, mas, em termos institucionais, constitui-se num avanço. Isso porque ele não era um simples programa; supunha uma normatização, leis municipais, reconhecimento da participação da sociedade nas assembléias e os seus representantes eram eleitos como delegados, o que requeria uma base institucional mais sólida para a sua realização.

Na gestão da prefeita Vilma de Faria (PSB), mais especificamente na segunda gestão, a participação da sociedade no processo de tomada de decisões foi constantemente ressaltado, principalmente através do Nosso Bairro Cidadão, mas, para nós, havia dois objetivos claros na implementação do referido programa na gestão analisada: primeiro, forjar um envolvimento da comunidade, no sentido de que, através desse programa, ocorreria a participação dela na tomada de decisões em relação a melhorias locais; segundo, responder, de forma imediata, a algumas necessidades da população. Nesse programa, o atendimento é feito à luz da política do favor, sendo necessária a presença da prefeita para garantir a imagem da importância do governante para a prestação de serviços para a população. A prefeita, com o seu discurso voltado para a idéia de que está desenvolvendo uma administração ancorada na participação popular e na prioridade às questões sociais, vem permanecendo no Executivo municipal com uma postura historicamente voltada para o atendimento dos interesses da sua clientela, ou seja, das lideranças comunitárias, e isso tem se revelado um requisito fundamental para a manutenção do seu prestígio político.

As gestões de Vilma de Faria e Kátia Born consistem, ao nosso ver, em exemplos típicos do peso da política clientelista e populista. O caráter de inovação de suas ações e sua forma de implementação demonstra o forte ranço de política tradicional que elas têm. O governo está centrado na sua pessoa, na rejeição de formas mais democráticas de se definirem prioridades, resolverem-se problemas e distribuir-se orçamento. 
Como não existe o real cumprimento dos direitos proclamados pela própria Constituição brasileira, o clientelismo se revela o único caminho possível a grande parte da população para a resolução de seus problemas. Uma vez que o controle das fontes locais de benefícios assim como da prestação de serviços está nas mãos da prefeita, é a ela que a população direciona as suas demandas, com o objetivo de ver suas necessidades atendidas, o que demonstra o forte viés paternalista da administração, o qual tem suas raízes na dependência social em que está parcela significativa da população, frente à extrema precariedade de sua situação econômica. Ao longo de nossa história política, esse tipo de relação se tornou um fator estruturante da ação de determinados atores políticos.

Nas administrações analisadas a política social tem sido formulada com total falta de conhecimento dos canais efetivos de participação democrática, o que demonstra que a sua implementação não está voltada somente para a garantia da expansão de direitos de cidadania, mas principalmente para atender à necessidade de fortalecimento da liderança política da governante. Faltou vontade política, por parte das governantes, de mudar as regras do processo decisório, principalmente pelo fato de elas entenderem a participação da sociedade apenas como uma participação consultiva, que se realiza através das audiências públicas concedidas às lideranças comunitárias, as quais se transformaram em meros informantes da realidade local. Portanto o que a realidade tem demonstrado, nos dois municípios, é que relações do tipo clientelista sobrevivem e adaptam-se a contextos democráticos, porque são utilizadas como uma eficiente estratégia política, uma vez que os governantes as adotam para servirem aos seus fins, o que encontra respaldo na desigualdade social e, acima de tudo, no quadro de pobreza dela decorrente.

Em linhas gerais, é importante dizer que tentativas foram feitas para inovar as gestões por nós analisadas, mas essas tentativas aos poucos foram sendo deformadas pela pressão política local e pelas dificuldades operacionais, o que fez com que as práticas 
conservadoras fossem reintroduzidas e a participação da sociedade acabasse sendo relegada a um segundo plano, sendo priorizada somente como um elemento do discurso das prefeitas.

Recebido em: 16.03.2010

Aprovado em: 05.05.2011

\section{Referências}

ALMEIDA, L. S. B.. Política e governo: a trajetória de Vilma de Faria na prefeitura de Natal. Natal: [s.n.], 2001.

ANDRADE, I. A. L. Políticas e poder: o discurso da participação. São Paulo: AD HOMINEM; Natal: Cooperativa Cultural da UFRN, 1997.

. A gestão participativa das políticas públicas: o desafio para os municípios do Nordeste. In: CADERNOS ADENAUER o Nordeste à procura da sustentabilidade, Rio de Janeiro, v. 3 , n. 5 , p. $51-68$, dez. 2002.

AVRITZER, Leonardo. Teoria democrática e deliberação pública. Lua Nova: Revista de cultura e política. São Paulo, n. 50, 2000.

BOBBIO, Norberto. O futuro da democracia. São Paulo: Paz e Terra, 2000 .

BOHMAN, James. Deliberative democracy and effective social freedom: capabilities, resources and opportunities. In: BOHMAN, James; REHG, William. Deliberative democracy: essays on reason and politics. Massachusetts: Institute of Technology, 1999.

CABRAL, J. Gestão da Prefeita Kátia Born - 1997/2001. Entrevistador: Lindijane de Souza Bento Almeida. Maceió, 2004. 1 cassete sonoro (60 min.).

CAVALCANTE, J. R. B.. Gestão da Prefeita Kátia Born - 1997/2001. Entrevistador: Lindijane de Souza Bento Almeida. Maceió, 2004. 1 cassete sonoro (60 min.). 
COHEN, Joshua; ROGERS, Joel. Secondary associations and democratic governance. In: ASSOCIATIONS and democracy. London/New York: Verso, 1995.

COLEMAN, J. S. Social Capital in the Creation of Human Capital. In: The American Journal of Sociology, Vol. 94, Supplement: Organizations and Institutions: Sociological and Economic Approaches to the Analysis of Social Structure. (1988), pp. S95-S120.

CÔRTES, Soraya Maria Vargas. Capital social, desigualdades sociais e sinergia das esferas pública e privada: municípios gaúchos nos anos noventa. (mimeografado)

DAGNINO, E. Democracia, teoria e prática: a participação da sociedade civil. In: PERISSINOTTO, R. M.; FUKS, M. (Orgs). Democracia: teoria e prática. Rio de janeiro: Relume-Dumará; Curitiba: Fundação Araucária, 2002.

DAHL, Robert A. Sobre a Democracia. Brasília: UnB, 2001.

DEMO, P. Participação e conquista. São Paulo: Cortez, 1996.

. Participação e planejamento. In: PARA a década de 90 : prioridades e perspectivas de políticas públicas. Brasília: IPEA / IPLAN, 1989.

DINIZ, E. Governabilidade, democracia e reforma do Estado: os desafios da construção de uma nova ordem no Brasil. In: DINIZ, E.; AZEVEDO, S. (Orgs.). Reforma do Estado e democracia no Brasil. Brasília: Editora UnB, 1997.

ESPING-ANDERSEN, G.. As três economias políticas do welfare state. Lua Nova: Revista de cultura e política, São Paulo, n. 24, p. 85-116, set. 1991.

EVANS, Peter (Org.). State-Society Synergy: government action and social capital in development. Berkeley, UC Berkeley, International and Area Studies Publications, 1997.

FERREIRA, Ângela Lúcia de Araújo. Estado e movimentos sociais urbanos: o caso de Natal. Natal: UFRN, 1990. (Anexo I) 


\author{
Estado e movimentos sociais urbanos: o caso de Natal. \\ Natal: UFRN, 1991. (Anexo II)
}

FISCHER, T. (Org.). Poder local: governo e cidadania. Rio de Janeiro: Fundação Getúlio Vargas, 1993.

FACHIN, R.; CHANLAT, A. Dos dilemas da gestão do município e do papel do gestor: lições da teoria e da experiência. In:

Governo Municipal na América Latina: inovações e perplexidades. Porto Alegre: Sulina/Ed. da Universidade/UFRGS, 1998.

FARIA, V. M. de. Gestão da Prefeita Vilma de Faria - 1997/2000. Entrevistador: Lindijane de Souza Bento Almeida. Natal, 2000. 1 cassete sonoro (60 min.).

FONT, J. (Coord.). Ciudadanos y decisiones públicas. Barcelona: Ariel, 2001.

FREY, Klaus. "Capital social, comunidade e democracia”. Política \& Sociedade: Revista de Sociologia Política/Universidade Federal de Santa Catarina. Programa de Pós-Graduação em Sociologia Política - v. 1, n. 2. 2003 - Florianópolis: UFSC: Cidade Futura, 2003.

HIRST, Paul. Associative democracy: new forms of economic and social governance. Amerherst: The University of Massachusetts Press Amherst, 1994.

HABERMAS, Jürgen. Popular sovereignty as procedure. In: BOHMAN, James; REHG, William. Deliberative democracy: essays on reason and politics. Massachusetts: Institute of Technology, 1999.

KLERING, L. R.. Experiências recentes em municípios brasileiros: os novos municípios e as conquistas da autonomia. In: FACHIN, R. C.; CHANLAT, A. Governo Municipal na América Latina: inovações e perplexidades. Porto Alegre: Sulina/Ed. da Universidade/UFRGS, 1998.

LAGOS, M. How people view democracy: between stability and crisis in Latin America. Journal of Democracy, v. 12, n.1, p. 137145, jan. 2001.

LEAL, Victor Nunes. Coronelismo, enxada e voto: o município e o regime representativo no Brasil. São Paulo: Alfa-Omega, 1978. 
LESSA, M. Q. M. Gestão da Prefeita Kátia Born - 1997/2001. Entrevistador: Lindijane de Souza Bento Almeida. Maceió, 2004. 1 cassete sonoro (60 min.).

LINS, Regina Dulce Barbosa. The myth of local government autonomy: findings from the study of the municipal government of Maceió in Alagoas, Brazil, from 1986 to 1988. Tese (Doutorado) - Universidade de Kent, Inglaterra, 1999.

LÜCHMANN, L. H. H. Possibilidades e limites da democracia deliberativa: a experiência do orçamento participativo de Porto Alegre. Campinas: [s.n.], 2002.

MASSOLO, A. Em direção às bases: descentralização e município. Espaço \& Debates, São Paulo, v.8, n.24, p. 40-54, 1988.

MEDEIROS, E. Gestão da Prefeita Vilma de Faria - 1997/2000. Entrevistador: Lindijane de Souza Bento Almeida. Natal, 2000. 1 cassete sonoro (60 min.).

MINEIRO, F. Gestão da Prefeita Vilma de Faria - 1997/2000. Entrevistador: Lindijane de Souza Bento Almeida. Natal, 2000. 1 cassete sonoro (60 min.).

MOISÉS, J. Á.; ALBUQUERQUE, J. A. G. Dilemas da consolidação da democracia. Rio de Janeiro: Paz e Terra, 1989.

NOGUEIRA, M. A. As possibilidades da política: idéias para a reforma democrática do Estado. São Paulo: Paz e Terra, 1998.

NUNES, Edson de Oliveira. Gramática política do Brasil: clientelismo e insulamento burocrático. Rio de Janeiro: Jorge Zahar, 1997.

OFFE, C. A atual transição da história e algumas opções básicas para as instituições da sociedade. In: PEREIRA, L. C. B., WILHEIM J., SOLA, L. (Orgs). Sociedade e Estado em transformação. São Paulo: Editora UNESP; Brasília: ENAP, 1999.

OLIVEIRA, F. de; PAOLI, M. C. (Orgs). Os sentidos da democracia: políticas do dissenso e a hegemonia global. Petrópolis: Vozes; Brasília: NEDIC, 2000.

PARDO, M. C. " La gestión municipal - Motor ou Freio para el ejercicio democratico?" In: MERINO, M. (coord.). En Busca de la Democracia Municipal: la participacion ciudadana en el gobbierno local mexicano. México: Centro de Estudios Internacionales, 1994. 
PASSOS, O. Gestão da Prefeita Vilma de Faria - 1997/2000. Entrevistador: Lindijane de Souza Bento Almeida. Natal, 2000. 1 cassete sonoro (60 min.).

PATEMAN, Carole. Participação e teoria democrática. Rio de Janeiro: Paz e Terra, 1992.

PEREIRA, M. L. D. L. Negociações e parcerias: a gestão urbana democrático participativa. São Paulo: [s.n.], 1999.

PUTNAM, R. Comunidade e democracia: a experiência da Itália moderna. Rio de Janeiro: FGV, 1996.

REIS, F. W. Democracia, igualdade e identidade. In: PERISSINOTTO, R. M.; FUKS, M. (Orgs). Democracia: teoria e prática. Rio de janeiro: Relume-Dumará; Curitiba: Fundação Araucária, 2002.

SANTOS, B. de S. Para uma reinvenção solidária e participativa do Estado. In: BRESSER-PEREIRA, L. C.; WILHEIM, J.; SOLA, L.. (Orgs). Sociedade e Estado em transformação. São Paulo: Editora UNESP; Brasília: ENAP, 1999.

. Democratizar a democracia: os caminhos da democracia participativa. Rio de Janeiro: Civilização Brasileira, 2002.

RIBEIRO, K. B. Gestão da Prefeita Kátia Born - 1997/2001. Entrevistador: Lindijane de Souza Bento Almeida. Maceió, 2004. 1 cassete sonoro (60 min.).

SILVA, Gustavo Tavares da. Democracia representativa e "gestão participativa". In: OLIVEIRA, Marcos Aurélio Guedes de (Org.). Política e Contemporaneidade no Brasil. Recife: Bagaço, 1997.

SANTOS, P. F. Gestão da Prefeita Kátia Born - 1997/2001. Entrevistador: Lindijane de Souza Bento Almeida. Maceió, 2004. 1 cassete sonoro (60 min.).

SILVA, A. L. P . Gestão da Prefeita Kátia Born - 1997/2001. Entrevistador: Lindijane de Souza Bento Almeida. Maceió, 2004. 1 cassete sonoro (60 min.).

SPINK, P. A democratização do poder local: gestão social na ótica subnacional. In: RICO, E.M.; RAICHELIS, R. (Orgs). Gestão social: uma questão em debate. São Paulo: EDUC; IEE, 1999. 
STEWART, J. De la innovación democrática a la democracia deliberativa. In: FONT, J. (Coord.). Ciudadanos y decisiones públicas. Barcelona: Ariel, 2001.

WEFFORT, F. C. O Populismo na política brasileira. Rio de Janeiro: Paz e Terra, 1980.

\begin{abstract}
The limits of participation: The municipal administrations of the Socialist Brazilian Party (PSB) in Natal and Maceió

The enlargement of civil society participation experiences in public management (at least as a proposal) has led to a great diversity of results even when executed by groups from the same political party or with the same ideological interests. Thus, we investigate why the participative management process takes place in different forms even when the managers belong to the same party and share the same ideas. The comparative analysis of the two experiences (Natal and Maceió) shows that there are similarities, nevertheless, although both are connected to the same political party project, there are also differences in the advance of such process mainly because of the basis work performed by the left parties among the popular movement, the kind of govern coalition which has been developed in the city, and by the institutional legacy left by the former administration.
\end{abstract}

Keywords: public management, social participation, democracy, clientelism. 